\title{
EDUCAÇÃO INCLUSIVA NA EAD: OPORTUNIDADES E DESAFIOS A PARTIR DA LITERATURA
}

CURITIBA/PR MAIO/2018

\author{
KARINA NONES TOMELIN - UP - karina.tomelin@up.edu.br \\ MARILIA PESSANHA - UP - marilia.pessanha@up.edu.br \\ IZABELLA ROMANETTO GONÇALVES - UP - izabella.romanetto@up.edu.br \\ ADRIANA PELIZZARI - UP - adriana.pelizzari@up.edu.br
}

Tipo: Investigação Científica (IC)

Natureza: Planejamento de Pesquisa

Categoria: Suporte e Serviços

Setor Educacional: EDUCAÇÃO SUPERIOR

\begin{abstract}
RESUMO
A mobilização deste estudo se deu pela necessidade de pensar políticas de apoio, acesso, permanência e conclusão de alunos da educação inclusiva na educação a distância. $O$ acesso deste público no ensino superior é recente e crescente. Na educação presencial, muitas vezes, há setores e pessoas destinadas a pensar ações e medidas de inclusão e acessibilidade. E na EAD? Que medidas e estratégias são necessárias para garantir a permanência destes alunos? A partir destas indagações, buscou-se na literatura internacional conhecer quais desafios e estratégias as instituições de ensino superior adotam para promover a permanência. Para tanto, foram consultados oito artigos estrangeiros. Os resultados indicaram uma tendência a utilização do desenho universal da aprendizagem (DUA) como estratégia proativa e preventiva da acessibilidade de estudantes da EAD além da definição de eixos e dimensões claras da acessibilidade institucional.
\end{abstract}

Palavras-chave: educação inclusiva, ensino a distância, ensino superior 


\section{INTRODUÇÃO}

O objetivo deste trabalho é levantar métodos e tecnologias inovadoras de acessibilidade aplicáveis à educação a distância por meio da literatura internacional. A necessidade deste estudo é buscar mecanismo para compreensão de como se estruturam as instituições de educação superior para garantir o acesso, a permanência e a conclusão dos estudantes na educação a distância com qualidade.

O desafio crescente dado pela ampliação do acesso dos estudantes público alvo da educação inclusiva e a ampliação de vagas na modalidade a distância nas instituições de educação superior no Brasil faz com que se promovam estudos e pesquisas buscando conhecer e disseminar estratégias de apoio a estes alunos.

O levantamento foi realizado em periódicos da CAPES em oito artigos dos Estados Unidos, Canadá e Reino Unido por meio das palavras-chave: distance learning e accessibility, distance education e accessibility.

\section{DESAFIOS DA EDUCAÇÃO INCLUSIVA}

Pensar os desafios para educação inclusiva no Brasil na educação presencial é algo recente, porém que vem se legitimando, não somente por dispositivos legais (por exemplo, os instrumentos regulatórios do Ministério da Educação e Cultura, a Política Nacional ou mesmo a Lei Brasileira de Inclusão), mas também pelo próprio acesso dos estudantes ao ensino superior. Os dados do Censo Escolar, realizados e divulgados pelo Instituto Nacional de Estudos e Pesquisas (INEP, 2017) evidenciam a crescente de estudantes com deficiência que acessam o ensino superior. Em dez anos, o aumento foi de seiscentos por cento.

Diante disto, algumas instituições de educação superior organizam espaços com foco na atenção, acesso, promoção e permanência destes alunos. Estes muitas vezes são estruturados em setores de atendimento que oferecem apoio psicopedagógico e adaptação aos estudantes na categoria de inclusão, formado por equipe multidisciplinar e professores das instituições (TOMELIN, 2018).

$\mathrm{Na}$ educação a distância no Brasil ainda não há dados que evidenciem como se estruturam as políticas e ações de permanência destes estudantes. A necessidade de conhecer o público da educação especial que acessa a EAD, as formas de mapeamento destes alunos, quantidade, estratégias de apoio, recursos tecnológicos de acessibilidade serão mapeados pela primeira vez pelo Censo da ABED em 2018. 


\section{RESULTADOS}

\section{O desenho universal da aprendizagem:}

Observa-se nos estudos investigados a presença da discussão sobre o desenho universal de aprendizagem. O desenho universal de aprendizagem (DUA) são estratégias que buscam uma desconstrução dos estereótipos e rótulos a partir de um olhar exclusivo, de adaptações e adequações, relacionado a deficiência e diagnósticos médicos. Essas estratégias visam a partir disso a eliminação de barreiras ao acesso ao conhecimento sem exclusividades, mas que todos sejam beneficiados. (BOCK, GESSER, NUERNBERG, 2018)

Esse conceito de DUA é bastante explorado internacionalmente, como podemos ver nos artigos pesquisados, mas no que diz respeito ao Brasil, é ainda pouco disseminado e estudado, o que repercute na prática. Atualmente há, em sua maioria, uma busca exclusiva de acesso à pessoa com deficiência ou necessidades nomeadas através de diagnósticos médicos.

É necessário através desse conceito (DUA) disseminar a singularidade do estudante e a busca de práticas que envolvam todos os sujeitos do processo de aprendizagem, não havendo foco em apenas uma situação (deficiência), mas sim para que todo o processo de aprendizagem seja sem barreiras.

Sassaki (2009) nomeia dimensões específicas de acessibilidade para que haja a eliminação de barreiras, mas ainda muito pensadas a partir da visão única de pessoa com deficiência. Pode-se unir ambos conceitos, dimensões de acessibilidade e desenho universal de aprendizagem, para se pensar em uma construção de acesso, permanência, participação e conclusão com qualidade ao público da EAD na educação superior, pensando assim em eliminação de barreiras para todos os estudantes matriculados nesta categoria.

$\mathrm{Na} E A D$, segundo os artigos pesquisados, o DUA é uma proposta apresentada em todos os espaços do curso à distância (materiais instrucionais, AVA, fóruns). Os autores discutem diferentes motivações para essa necessidade. No estudo realizado por Roberts, Crittenden e Crittenden, J. (2011), 69,7\% dos estudantes com deficiência não declararam sua condição para a instituição de ensino, de forma que suas necessidades específicas não podem ser atendidas em sistemas de acessibilidade sob demanda (i.e.: somente por adaptações específicas). Estes autores associam a falta de identificação dos estudantes aos fatores internos e externos apontados em pesquisas anteriores: 
"não entender como os serviços de acessibilidade estão disponíveis, despreparo ou intimidação de interagir pessoalmente com os funcionários da instituição, vontade de um novo começo sem ser rotulado, medo de ser considerado incapaz pelos colegas ou funcionários (GETZEL AND THOMAS 2008 apud ROBERTS, CRITTENDEN E CRITTENDEN 2011, tradução nossa). O desenho universal, em contrapartida, é a promoção da inclusão de forma proativa, preventiva e efetiva. Slater, Pearson, Warren e Forbes (2015) indicam que uma produção de currículo inclusiva é financeiramente mais viável do que adaptações posteriores, que podem inclusive ser impraticáveis em tempo hábil para apoiar o estudante.

Burgstahler, Corrigan e McCarter (2004) observam ainda que formatos acessíveis são mais bem aproveitados por todas pessoas, inclusive as que não tem deficiências: vídeos legendados para surdos podem apoiar estudantes que não podem ouvir os áudios por estudarem de madrugada ou a descrição de imagens para cegos pode apoiar estudantes com problemas de conexão à internet.

Adaptações individuais:

Mesmo com um formato acessível para a maioria das pessoas, algumas adaptações individuais serão necessárias. Para determinar se a adaptação será feita, a própria instituição deve desenvolver um processo de decisão. A fim de respaldar-se diante de eventuais negativas a solicitações de estudantes a Universidade Aberta do Reino Unido (OU) tem o seguinte processo de decisão:

- O estudante está em desvantagem substancial por causa da sua deficiência?

- É viável e efetivo providenciar uma adaptação?

- Essa adaptação poderia ser feita por meio de DSA?

- Essa adaptação é viável financeiramente?

Cabe observar que este tipo de processo deve considerar a realidade local, tanto sob o aspecto de legislação local quanto da realidade da própria instituição. No caso da OU, um dos passos envolve a utilização da DSA, um financiamento governamental destinado a pessoas com deficiência e aos seus custos educacionais decorrentes da deficiência, um traço muito específico da política daquele país (SLATER, PEARSON, WARREN e FORBES, 2015).

Para os casos de adaptações específicas, as rotas de solicitação, os contatos dos responsáveis e a política de acessibilidade devem ser informações públicas e fáceis para o estudante localizar, a fim de que a implementação das adaptações necessárias 
seja feita em tempo hábil (BURGHSTAHLER, CORRIGAN e CORRIGAN, 2004)

A tecnologia na Ead:

Além das questões de natureza educacional, a acessibilidade na EAD perpassa questões de natureza técnico-estrutural. A esse respeito, Harper e DeWaters (2008) destacam o uso de recursos como o programa Watchfire Bobby, que faz a verificação de sites, a fim de observar se estão adequados à legislação estadunidense de acessibilidade e às Diretrizes de Acessibilidade para Conteúdo Web (WCAG). Essas diretrizes podem ser acessadas em português através do endereço https://www.w3.org/Translations/WCAG20-pt-PT/. As autoras apresentam ainda estratégias para a construção/adaptação de recursos virtuais.

\section{Quadro 1: Implementações rápidas de acessibilidade em material virtual (requisitos técnicos)}

\section{Característica daOrientação de acessibilidade}

\section{página}

Imagens e animações Imagens e animações: usar o atributo alt para descrever a função de cada recurso visual

Mapas em imagem Use mapa e texto client-side para hotspots

Multimídia Providenciar legendas e transcrições dos áudios e descrição do vídeo

Links

Utilizar textos que façam sentido em diferentes contextos (evite clique aqui)

Organização da página Use cabeçalhos, listas e estrutura consistente. Usar página em cascata (layout e estilo) sempre que possível

Scripts, applets, plug-ins Providenciar conteúdo alternativo se os recursos forem nãoacessíveis

Gráficos e figuras Sumarizar ou usar o atributo longdesc

Frames Utilizar o elemento no frames e títulos significativos

Tabelas Sumarizar. Facilitar a leitura linha-a-linha.

Verificação do trabalho Validação

Adaptado de Anderson 2004 apud Harper e DeWaters (2007)

Especialista em acessibilidade: 
A fim de construir os cursos de forma acessível e atender às demandas específicas, a Universidade Aberta do Reino Unido desenvolveu um programa de acessibilidade, reestruturando a forma com que todos os setores da universidade trabalhavam (equipes de suporte técnico ao aluno, tutores e de criação de conteúdo). Dentro de cada time/setor, um colaborador foi capacitado para ser o especialista de acessibilidade, sendo alguém que conhecia a temática específica daquele grupo de disciplinas e também os fluxos da instituição; esse profissional era responsável por articular a acessibilidade no cotidiano do setor. A estratégia de acessibilidade é pulverizar a responsabilização da inclusão em todos os setores acadêmicos da instituição. (SLATER, PEARSON, WARREN e FORBES, 2015).

\section{Eixos da acessibilidade:}

A Universidade de Washington possui uma estratégia de promoção da acessibilidade na EAD orientada sobre sete eixos de ação (BURGHSTAHLER, CORRIGAN e MCCARTER, 2004): (i) apoio institucional, (ii) desenvolvimento de cursos, (iii) ensino/aprendizagem, (iv) estrutura do curso, (v) apoio ao estudante, (vi) apoio aos colaboradores da instituição e (vii) avaliação e validação.

- Apoio institucional diz respeito ao desenvolvimento de políticas e projetos de acessibilidade que sejam reconhecidos como documentos válidos da IES, ou a inclusão dessa temática nas políticas já existentes.

- Desenvolvimento do curso refere-se a apresentar padrões mínimos a serem encaminhados para as equipes de webdesign e estruturação dos cursos, tanto para criação quando para revisão periódica dos cursos.

- Ensino/aprendizagem compreende a promoção de diversas formas de interação com tutores e colegas, a fim de atender a maior variedade de alunos.

- Estrutura do curso compreende fornecer (a) informações claras aos estudantes sobre a especificação técnica mínima para conseguir rodar os recursos de acessibilidades e (b) informações específicas sobre as possíveis barreiras específicas de cada curso, além de (c) manter bibliotecas físicas e virtuais adequadas, inclusive com computadores com recursos de acessibilidade (para estudo em casa, o próprio estudante deve ser responsabilizado pelo seu equipamento).

- Apoio ao estudante diz respeito a ter setores dedicados ao apoio a estudantes, sendo esses caminhos para apoio técnico e serviços de acessibilidade/inclusão facilmente localizáveis pelo estudante. Também devem ser promovidas ações de apoio aos colaboradores da instituição, como a criação de páginas/manuais de como lidar com pessoas com deficiência e a manutenção de um canal aberto de 
comunicação com o setor de acessibilidade.

- Avaliação e validação prevê a verificação da qualidade do material produzido, revisando e aprimorando periodicamente.

Além dos eixos os autores descrevem ainda sugestões a partir do desenvolvimento de processos claros para promoção da acessibilidade na EAD:

\section{Quadro 2: Implementação de um processo de ensino à distância acessível}

\section{Área de interesse}

Política

Padrão

Procedimentos

Disseminação

Treinamento e suporte Premiação/reforço

Avaliação e revisão

\section{Sugestão}

Rever as políticas existentes na instituição, a fim de corrigir ou incluir a premissa da acessibilidade. Não esquecer de que as políticas devem conter tanto o desenho universal quanto as adaptações necessárias.

Adotar um padrão de acessibilidade web (ex: WCAG) ou desenvolver um padrão da própria instituição

Incluir o padrão de acessibilidade no modelo solicitado aos criadores de conteúdos novos (designers instrucionais, conteudistas, instrutores)

Repassar a política e os procedimentos com frequência aos estudantes e equipes.

Fornecer apoio às equipes da universidade

Recompensar os times que fazem esforços excepcionais na criação de materiais acessíveis ou na inclusão deste tema nos seus materiais

Periodicamente avaliar a qualidade da acessibilidade dos cursos, corrigindo-os constantemente. Incluir pessoas com deficiência nessa etapa.

Elaborado a partir de Burghstahler, Corrigan e Corrigan 2004.

A Universidade de Washington possui ainda um programa de parceria internacional na promoção de boas práticas de acessibilidade EaD, além de recursos diversos como manuais e grupos de discussão (ver www.washington.edu/doit/Resources/accessdl.html ).

\section{CONSIDERAÇÕES FINAIS}

O levantamento bibliográfico indicou como forte tendência da promoção da 
acessibilidade na EAD e a utilização do desenho universal da aprendizagem. Tal estratégia garantiria o acesso de forma preventiva a todos os estudantes de maneira indiscriminada.

Além disto, observa-se a preocupação e utilização das tecnologias educacionais como aliadas ao processo de inclusão, não somente como recurso de aprendizagem, mas também como mapeamento da acessibilidade institucional.

Outro ponto importante é pensar a acessibilidade em diferentes dimensões (comunicacional, metodológica, programática, tecnológica) para garantir que pessoas sejam engajadas e processos sejam mais facilmente apreendidos por todos que atuam na EAD (SASSAKI, 2009).

\section{REFERÊNCIAS}

BOCK Geisa Letícia Kempfer, GESSER Marivete, NUERNBERG Adriano Henrique. Desenho Universal para a Aprendizagem: a Produção Científica no Período de 2011 a 2016. Rev. bras. educ. espec. vol.24 no.1 Bauru Jan./Mar. 2018.

BURGSTAHLER, Sheryl; CORRIGAN, Bill; MCCARTER, Joan. Making distance learning courses accessible to students and instructors with disabilities: A case study. The Internet And Higher Education, [s.I.], v. 7, n. 3, p.233-246, jul. 2004. Elsevier BV. http://dx.doi.org/10.1016/j.iheduc.2004.06.004

INEP. Censo Escolar MEC/INEP. Disponível em: http://portal.mec.gov.br/index.php?option=com_docman\&view=download\&alias $=16759-p$ rincipais-indicadores-da-educacao-de-pessoas-com-deficiencia\&ltemid=30192> Acesso em: 29 de abril de 2017.

HARPER, Kelly A.; DEWATERS, Jamie. A Quest for website accessibility in higher education institutions. The Internet And Higher Education, [s.I.], v. 11, n. 3-4, p.160-164, jan. 2008. Elsevier BV. http://dx.doi.org/10.1016/j.iheduc.2008.06.007.

ROBERTS, Jodi B.; CRITTENDEN, Laura A.; CRITTENDEN, Jason C.. Students with disabilities and online learning: A cross-institutional study of perceived satisfaction with accessibility compliance and services. The Internet And Higher Education, [s.I.], v. 14, n. 4, p.242-250, set. 2011. Elsevier BV. http://dx.doi.org/10.1016/j.iheduc.2011.05.004.

SLATER, Rachel et al. Institutional change for improving accessibility in the design and 
delivery of distance learning - the role of faculty accessibility specialists at The Open University. Open Learning: The Journal of Open, Distance and e-Learning, [s.I.], v. 30, n. $1, \quad$ p.6-20, 2 jan. $2015 . \quad$ Informa UK Limited. http://dx.doi.org/10.1080/02680513.2015.1013528.

SASSAKI, Romeu Kazumi. Inclusão: acessibilidade no lazer, trabalho e educação. Revista Nacional de Reabilitação (Reação), São Paulo, Ano XII, mar./abr. 2009, p. $10-16$

TOMELIN K.N, DIAS A.P.L, SANCHEZ C.N.M, PERES J, CARVALHO S. Educação inclusiva no ensino superior: desafios e experiências de um núcleo de apoio discente e docente. Rev.Psicopedagogia: 2018; 35(106):94-103 